\title{
FiSyPAC project: The first vehicle integration of GENEPAC fuel cell stack
}

\author{
F. ROY ${ }^{1}$, J. P. POIROT ${ }^{2}$, S. GARNIT ${ }^{3}$ \\ ${ }^{1}$ PSA Peugeot Citroën, Carrières-sous-Poissy, France, email: francis.royl@mpsa.com \\ ${ }^{2}$ CEA-LITEN, F-38054, Grenoble,France,email: jean-philippe.poirot@cea.fr \\ ${ }^{3}$ PSA Peugeot Citroën, Carrières-sous-Poissy, France, email: sadok.garnit@mpsa.com
}

\begin{abstract}
In January 2006, the first fuel cell stack developed by the partnership between PSA Peugeot Citroën and CEA has been unveiled. Due to its particularly high performances, $1,5 \mathrm{~kW} / 1,1 \mathrm{~kW} / \mathrm{kg}$, with high efficiency vehicle integration has been launched out into the FiSyPAC project.

PSA group is committed to the long term, gradual integration of fuel cell technology into cars, by developing an innovative electric vehicle concept equipped with a range extender consisting of a hydrogenpowered fuel cell hybridized with a high battery capacity.

CEA is involved in the development of innovative technical solutions for fuel cells, particularly PEMFC in terms of stack design and fuel cell systems optimization for reliability and durability improvements.

The scope of the FiSyPAC project which joined eleven partner's forces is to develop a reliable $20 \mathrm{~kW}$ fuel cell system, a Li-ion battery, and to test this hybridization on board a Zero Emission Vehicle (ZEV).

A description of the vehicle architecture and performances achieved during the project are described in this paper, from the stack and fuel cell system design to the vehicle performances.
\end{abstract}

Keywords: Fuel Cell, Lithium battery, $\mathrm{HeV}, \mathrm{ZeV}$, Vehicle performance

\section{Introduction}

The first fuel cell stack developed by the partnership between PSA Peugeot Citroën and CEA has been unveiled in January 2006. This fuel cell stack has a rated power of $80 \mathrm{~kW}$ (Figure 1). It has been designed for the automotive application, taking into account several objectives, such as compactness, modularity, efficiency and compatibility with the constraints of mass production and vehicle integration [1], [2]. This stack is the result of a three years' study, associating competences from various skills, like electrochemistry, mechanics, electricity, thermal management, fluid mechanics, materials science and manufacturing processes.

Following this successful realization, it has been decided to optimize and integrate this technology on board a Zero Emission Vehicle (ZEV) in the frame of the FiSyPAC project.

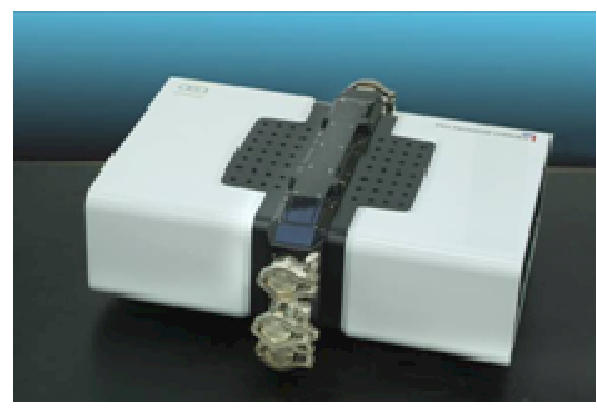

Figure 1: The GENEPAC Fuel Cell Stack $(80 \mathrm{~kW})$

The scope of this new project is to develop an electric vehicle integrating two power sources, a fuel cell system and its hybridization with a Li-ion battery. For this challenge, eleven partners were involved working on the different parts of the vehicle to achieve targets in terms of efficiency and reliability. 


\section{The fuel cell stack}

\subsection{General characteristics of the GENEPAC design}

In the frame of the GENEPAC project, the stack components were designed to ensure a good compactness, necessary for vehicle integration: $1.5 \mathrm{~kW} / \mathrm{L}$ and $1 \mathrm{~kW} / \mathrm{kg}$. Those values have been improved during the FiSyPAC project by the use of new bipolar plate material, and new MEA (Membrane Electode Assembly). Thus, the gain in performance for a given stack size is about $20 \%$.

The GENEPAC stack consisted of a central fluid distributor connected to four $20 \mathrm{~kW}$ fuel cell modules. Fastened to the distributor, the fuel cell fluid manifolds included air, hydrogen and coolant intakes and outlets, on opposite sides of the distributor. The FiSyPAC stack has been tailored on the GENEPAC's modular architecture basis. It is composed of 2 elementary stacks fastened on a fluid distributor (Figure 2).

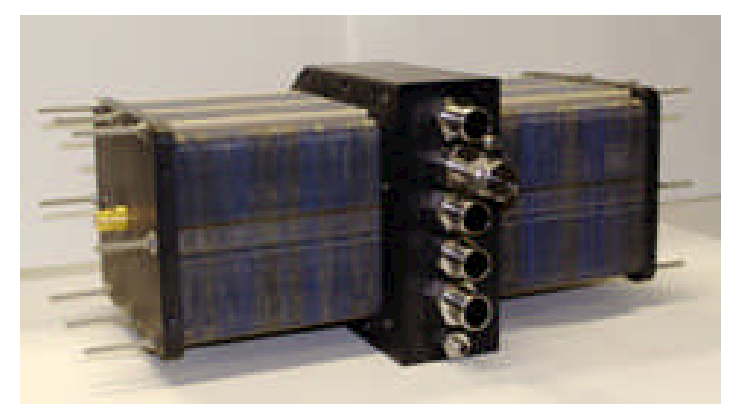

Figure 2: FiSyPAC $20 \mathrm{~kW}$ stack

The bipolar plates are based on a technology using metallic foils (stainless steel) that are stamped and laser welded. They integrate 3 different tiny flow channels in a minimal thickness. These channels diffuse the air and hydrogen onto the surface of the MEA, [1]. and the coolant flows between the 2 metallic foils constituting the bipolar plate.

Numerical simulations were used in order to evaluate reactants, coolant and mechanical forces distributions. For instance, the coolant flow field design guarantees the temperature homogeneity along the bipolar plate during stack operation (Figure 3).

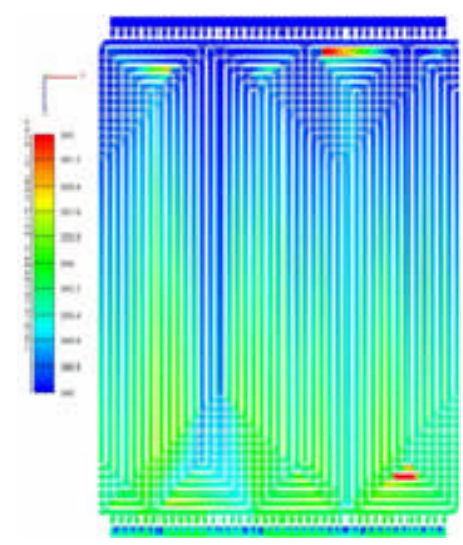

Figure 3: Temperature distribution in a bipolar plate

During FiSyPAC project the work has been focused on the optimisation of the compatibility of the material with the different media in the fuel cell, taking into account corrosion resistance and electrical contact resistance as mentioned in different studies [3], [4]. New metals and coatings have been tested, in the aim of increasing material compatibility and decreasing the cost.

Several MEA samples were tested during the selection phase of GENEPAC project. In the frame of FiSyPAC, some new samples were integrated in stacks in order to select a new product. As a result, our stack now exhibits up to $20 \%$ more power for the same efficiency, and a lifetime of more than 2200 hours.

\subsection{Bipolar plates}

Several metals and coatings have been evaluated by means of two types of tests : ex-situ resistance measurements and in-situ test as a real bipolar plate inside a fuel cell stack.

The first experiments have been used to select the best materials, coatings and coating thicknesses. Tests are made on a test stand INSTRON 4465 dedicated to mechanical characterization of samples [5]. This device has been adapted with specific instruments allowing the measurement of the electrical contact resistance as a function of the compression (Figure 4). This resistance is obtained from the Ohm law. A given current is applied through the sample from two copper rods. The resulting voltage is measured between the two materials in contact: the tested metal and a Gas Diffusion Layer (GDL). 


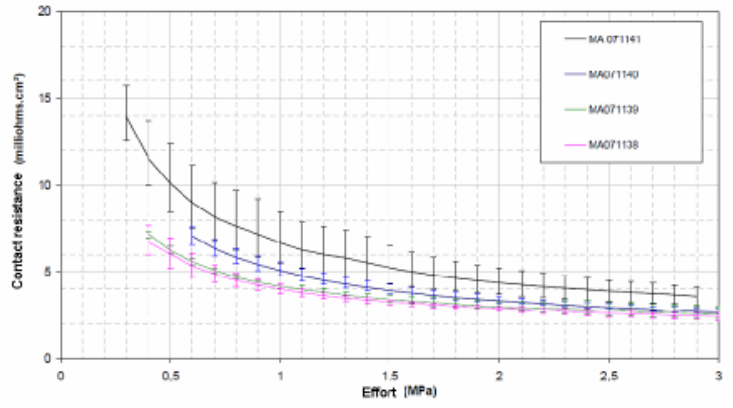

Figure 4: Ex-situ contact resistance measurement

The in-situ tests are made with bipolar plates realized with the tested material. It is then possible to check the formability and the weldability of the material. By this manner, we have been able to reject one sample which had exhibit a good contact resistance during the exsitu test, but which couldn't be formed to make a bipolar plate.

We have also checked the possibility to put some coatings on the metal sheets before the stamping and welding processes. A substantial cost reduction of the coating process can be achieved with the technique. The first results show that it's a promising way for coating deposition.

The in-situ results are focused on the electrochemical performance of the stack (polarization curves). Lifetime comparison has been made only with short test, in order to detect an eventual accelerated ageing of the coating. For longer tests, in most of the cases, lifetime is limited by the MEA degradation. Figure 5 shows the performance comparison between several coatings deposited on the same base material (stainless steel). Tests are made with 6 cells stacks, which have proved to be representative of longer stacks [1]. Coating B appears to be very promising, as it behaves well in terms of durability for several hundreds of hours. It still has to be tested on longer times (compatibility with MEAs over 5000 hours).

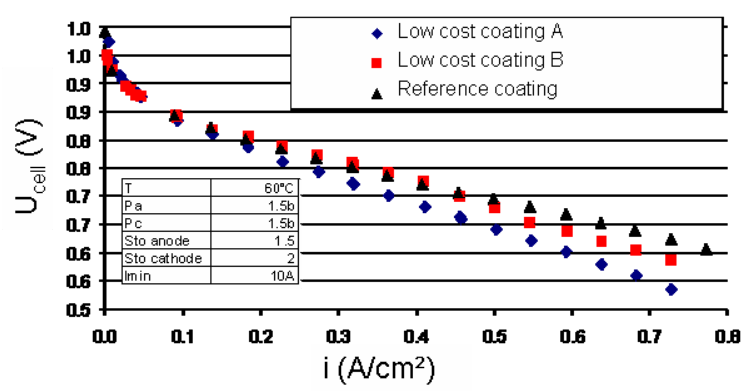

Figure 5: Polarization curves with different coatings

\subsection{MEA}

MEAs remain the key component influencing stacks performance and durability. During FiSyPAC project, one of the objectives was to implement new generations of MEA in order to obtain stacks with a better power density and a lower degradation rate.

Figure 6 gives a performance comparison between the standard GENEPAC MEA and a new generation MEA. The power density increase is about $20 \%$. As the GENEPAC hardware has many fixed characteristics, the MEAs had to fit perfectly with the present design in terms of geometrical dimensions, but also of mechanical properties, thickness of the different layers, etc.

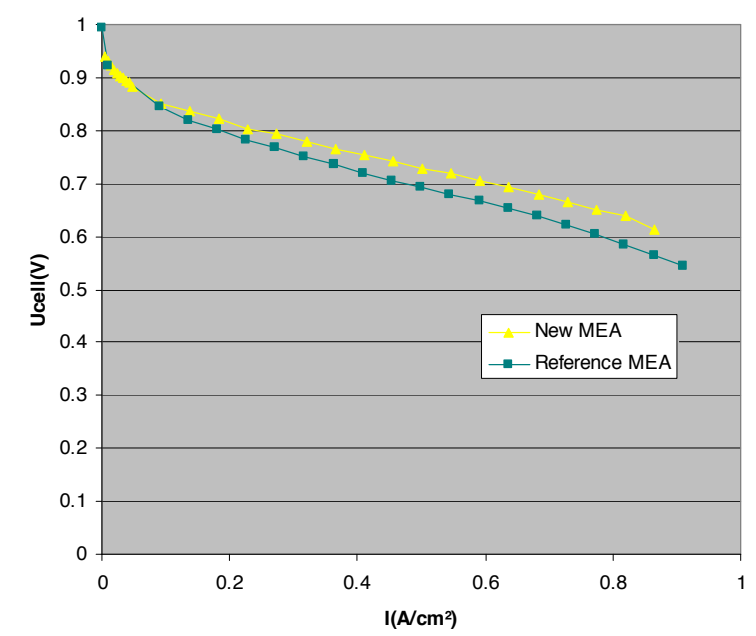

Figure 6: Polarization curve of new MEAs in GENEPAC hardware

At the same time, the stack lifetime has been significantly increased. It has been evaluated with the use of a specific automotive cycle established by PSA. It is a coupling of 4 driving types (city very low speed; city - low speed; road - medium speed; motorway - high speed). These elementary cycles are assembled to create a complete mixed cycle, representative of one day of driving.

Following the cycle, GENEPAC stacks with new MEAs exhibit a lifetime over 2200 hours.

\section{Fuel Cell system (FCS)}

\subsection{Architecture}

The fuel cell combines hydrogen and oxygen from the air to produce power, water, and heat. These reactions must be carried out at a suitable temperature, pressure and humidity for fuel cell 
operation. The FCS is built around the fuel cell to supply air, hydrogen and coolant, and remove the depleted reactants and heat that are produced by the reactions in the cells.

The FCS and the battery are the main sources of electric energy onboard. It provides about $20 \mathrm{~kW}$ net power to the vehicle at high efficiency.

The FCS is classically made up of the following five parts:

- Fuel Cell

- Hydrogen line

- Air line

- Coolant line

- Supervisor

The figure below describes the components of the FCS:

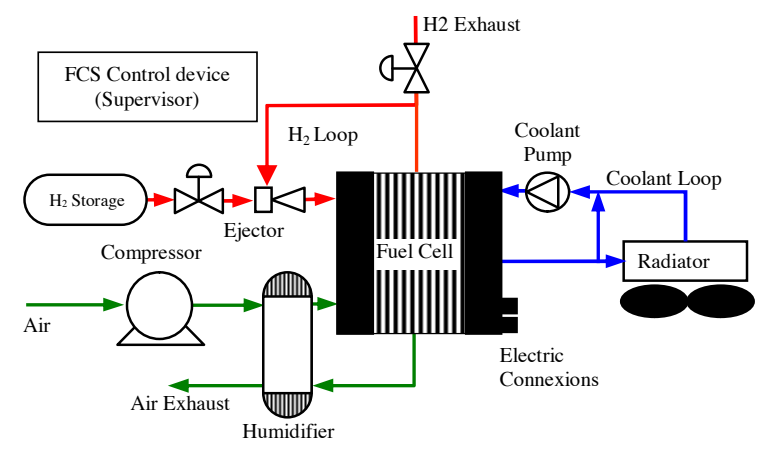

Figure 7: FCS organic architecture

There are several innovations in this architecture. The most important are the following ones:

- Hydrogen loop using an ejector

- Air supply using a centrifugal compressor with a passive humidifier without any storage of liquid water

- Thermal management using a three way valve

- Secure exhaust gases management (less then $75 \%$ LEL $_{2}$ )

The various lines were assembled, independently from each other on table for development of their respective control. Then they were assembled together for the final synthesis and performance evaluation (maximum power, output, dynamic...).

The figure below gives a global view of the FCS integration onboard.

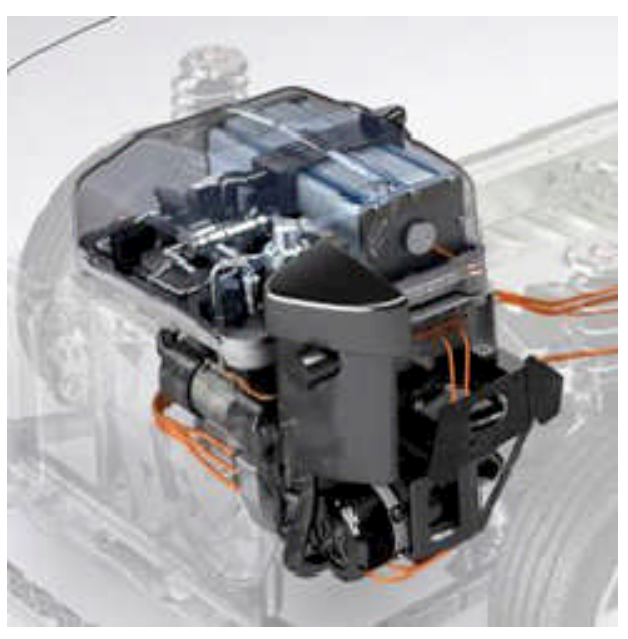

Figure 8: FCS Integration onboard

\subsection{Results}

\subsubsection{Operating conditions}

The operating conditions of the FCS on bench are the following ones:

Table 1: FCS operating conditions

\begin{tabular}{|l|l|}
\hline \multicolumn{1}{|c|}{ Parameters } & \multicolumn{1}{c|}{ Value } \\
\hline FC temperatures & $60^{\circ} \mathrm{C}-70^{\circ} \mathrm{C}-75^{\circ} \mathrm{C}$ \\
\hline $\begin{array}{l}\text { Hydrogen FCS } \\
\text { entrance pressure }\end{array}$ & 17 bars \\
\hline $\begin{array}{l}\text { Air \& } \mathrm{H}_{2} \text { operating } \\
\text { pressure }\end{array}$ & $1,1-1,5$ bar \\
\hline Air stoichiometry & $1,8-2,5$ \\
\hline Air humidity & $\begin{array}{l}\text { More than 50\% @ } \\
\text { FC temperature }\end{array}$ \\
\hline Current & $20 \mathrm{Amps}-140 \mathrm{Amps}$ \\
\hline Current step & $0 \rightarrow 140 \mathrm{Amps}$ \\
\hline Coolant flow & $50 \mathrm{Nl} / \mathrm{min}$ \\
\hline
\end{tabular}

The ejector was dimensioned to ensure a 1.5 hydrogen stoichiometry. It has been the subject of a specific organic validation.

\subsubsection{Stationary behavior}

The electric behavior of the fuel cell was very stable during these tests. The figure below gives the electric performances of the stack under the operating conditions stated above. 


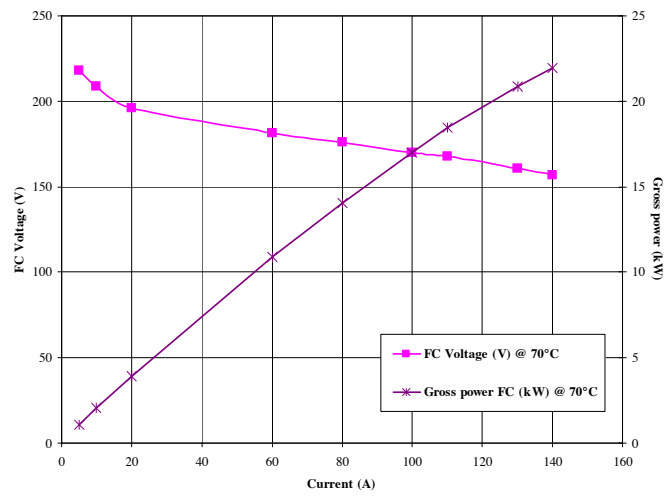

Figure 9: FCS stationary behaviour

The best electric performances of the FCS are obtained for an operating temperature of $75^{\circ} \mathrm{C}$.

The efficiency of the humidifier becomes better when the operating temperature of the FC increases. The air hygrometry is overall higher than $60 \%$.

The consumed hydrogen was measured using a mass flow meter located on the entrance of the FCS. These measurements take into account consumption as well as losses in the purging.

The efficiency is calculated using this formula:

$\eta_{F C S}=\frac{W_{F C \text { Gross }}-\frac{W_{\text {Compressor }}}{\eta_{D C / D C}}}{\text { Mass flow } H_{2} \cdot \text { LHV of } H_{2}}$

The graph below represents the efficiencies of the fuel cell system on the basis of LHV of hydrogen. The losses in the purging, the consumption of the compressor, and the efficiency of $\mathrm{HT} / \mathrm{HT}$ converter were taken into account in the calculation.

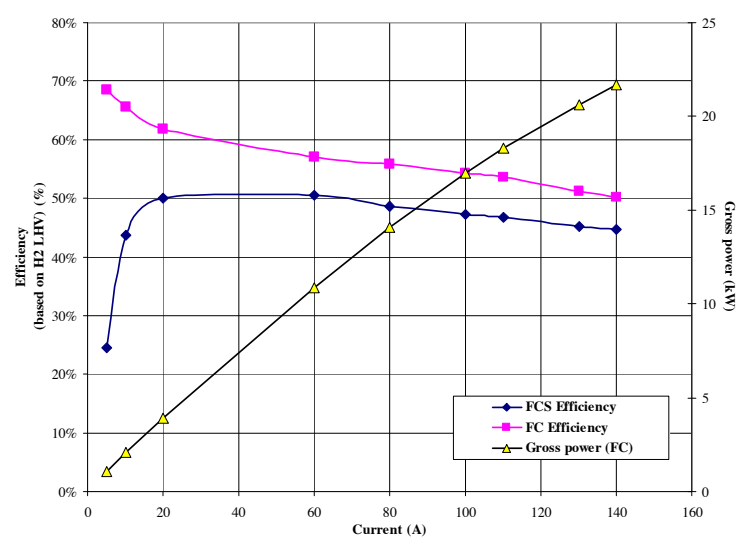

Figure 10: FCS stationary efficiency

At the nominal current (110A), the efficiency of the FC is about $54 \%$, and FCS one is closed to
$47 \%$. It is nearly constant on the overall operating range from 20 to $140 \mathrm{~A}$. It can be improved by optimizing operating condition of the compressor. The compressor offers in premium a noiseless working, which is extremely appreciated for automotives applications.

\subsubsection{Dynamic behavior}

The FCS response time to a step of current of $140 \mathrm{~A}$ is less than 4 seconds. The results of the dynamic tests are shown on the following figure:

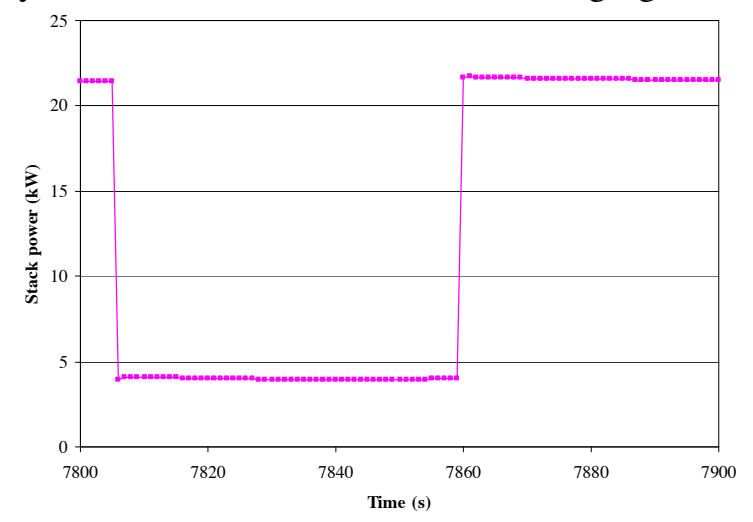

Figure 11: FCS dynamic behavior (130 amps step)

The response time of the FCS is driven by the dynamic compressor behavior.

\subsubsection{FCS performances}

The performances of the FCS design are resumed in the following table:

Table 2: FCS characteristics

\begin{tabular}{|r|l|}
\hline \multicolumn{1}{|c|}{ Parameters } & \multicolumn{1}{|c|}{ Value } \\
\hline Net Power mominal & $17 \mathrm{~kW}$ \\
\hline peak & $24 \mathrm{~kW}$ \\
\hline $\begin{array}{l}\text { Efficiencies } \\
\text { (based on H2 LHV) }\end{array}$ & \\
\hline @ Nominal power & $50 \%$ \\
\hline @ Maximal power & $47 \%$ \\
\hline @ Peak power & $44 \%$ \\
\hline Overall masse & $80 \mathrm{Kg}$ \\
\hline Voltage & $72-265 \mathrm{~V}$ \\
\hline Current & $180 \mathrm{Amps}$ max \\
\hline Dynamic response & $4 \mathrm{~s}$ to $100 \%$ net power \\
\hline
\end{tabular}




\section{The vehicle}

\subsection{Architecture}

The vehicle has been built on a basis of a Peugeot $307 \mathrm{CC}$ platform, transformed to integrate a $70 \mathrm{~kW}$ electric power train

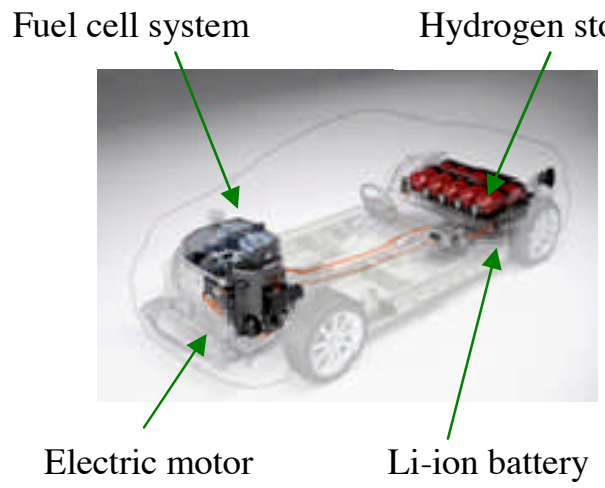

Figure 12: vehicle architecture

The electric motor is a synchronous brushless technology with a maximum torque of $180 \mathrm{Nm}$, coupled to the transmission by a speed reducer.

The Li-ion battery developed specifically for the project has a capacity of $13 \mathrm{kWh}(100 \mathrm{Wh} / \mathrm{l}$ and $88 \mathrm{Wh} / \mathrm{kg}$ ). It gives a driving range up to $75 \mathrm{~km}$ on NEDC cycle. The battery is charged by recovered braking energy, by the fuel cell or can be connected to the main (plug in function).

The high pressure storage tank has been designed to contain up to $4,2 \mathrm{~kg}$ of hydrogen at 700 bars.

\subsection{Vehicle performances}

The vehicle integrates an operating mode switch to drive the vehicle only with the battery or in a hybrid mode. The hybrid mode uses the FCS and the battery. The energy management of the two electric power sources is being aimed at optimising vehicle efficiency and FCS reliability. The vehicle integrates a regenerative braking to save energy and increase vehicle range.

Nowadays only pure electric mode has been evaluated on tracks and on a dynamometer tests bench. In the same time a specific dynamometer test bench has been equipped with a hydrogen supply. So that, final test will be provided in the next few weeks on hybrid mode.

Range and consumption measurements will be performed using the R101 regulation adapted by different European automakers during the European project FUEVA.

Using results of power consumptions and efficiencies measurement of components and subsystems, hydrogen consumption of the vehicle has been estimated at $1,1 \mathrm{~kg} / 100 \mathrm{~km}$.

It should be noted that the longitudinal dynamic performance of the vehicle is as good as a combustion engine with a higher torque at low speed and noiseless drive.

Table 3: Vehicle performances

\begin{tabular}{|c|c|}
\hline Top speed & $155 \mathrm{~km} / \mathrm{h}$ \\
\hline $0-60 \mathrm{~km} / \mathrm{h}$ & $6,9 \mathrm{~s}$ \\
\hline $0-100 \mathrm{~km} / \mathrm{h}$ & $16,6 \mathrm{~s}$ \\
\hline $1000 \mathrm{~m}$ Standing start & $38 \mathrm{~s}$ \\
\hline $\begin{array}{r}\text { on battery } \\
\text { on hybrid mode }\end{array}$ & $\begin{array}{c}75 \mathrm{~km} \\
\text { Close to } 500 \mathrm{~km}\end{array}$ \\
\hline $\begin{array}{l}\text { Hydrogen consumption on } \\
\text { NEDC cycle (simulation) }\end{array}$ & $\sim 1,1 \mathrm{~kg} / 100 \mathrm{~km}$ \\
\hline
\end{tabular}

\section{Conclusion}

Due to the high costs of this technology, PSA group is committed to the long-term, gradual integration of fuel cell technology into cars, with an initial focus on urban delivery or leisure vehicle fleets. In line with this commitment, PSA Peugeot Citroën is developing innovative hybrid electric vehicle concept equipped with a hydrogenpowered fuel cell and battery. FiSyPAC vehicle is one of the best illustrations of such a range extender concept car, with a particularly good dynamic behaviour and range.

This project has proven the ability of the GENEPAC stack concept to be integrated into a vehicle. Moreover, each parts of the vehicle including the fuel cell stack and system have been improved and optimised in order to obtain good efficiency and reliability.

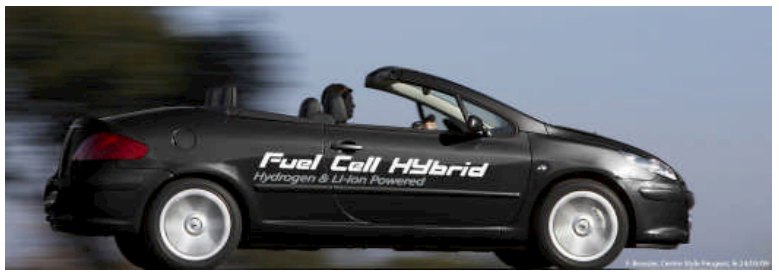

Figure 13: FiSyPAC vehicle picture

\section{Acknowledgments}

This work is funded in part by Agence Nationale de la Recherche (French National Research Agency). 


\section{FiSyPAC Partners}

Peugeot Citroën Automobiles

CEA

L2ES-UTBM

SAFT

BERTIN TECHNOLOGIES

SHERPA ENGINEERING

3D-PLUS

ARCELORMITTAL Stainless and nickel alloys

ARCELORMITTAL Innovation

SOPRANO

EMC

\section{References}

[1] L. Antoni, X. Glipa, F. Roy, J.-P. PoirotCrouvezier, Pile à combustible GENEPAC, Techniques de l'Ingénieur, [IN52], Base Génie Energétique, Rubrique Convertisseurs Primaires et Vecteurs d'Energie (2007)

[2] J.-P. Poirot-Crouvezier, F. Roy, GENEPAC Project: Realization of a fuel cell stack prototype dedicated to the automotive application, WHEC 2006

[3] V. Mehta and J.S. Cooper, Review and analysis of PEM fuel cell design and manufacturing, Journal of Power Sources 114 (2003), pp. 32-53

[4] W. Schmittinger, A. Vahidi, A review of the main parameters influencing long-term performance and durability of PEM fuel cells, Journal of Power Sources, 180 (2008), pp. 1-14

[5] J. André, L. Antoni, J.-P. Petit, E. De Vito, A. Montani Electrical contact resistance between stainless steel bipolar plate and carbon felt in PEFC: A comprehensive study, International Journal of Hydrogen Energy, Vol. 34, Issue 7, April 2009, pp. 3125-3133

\section{Authors}

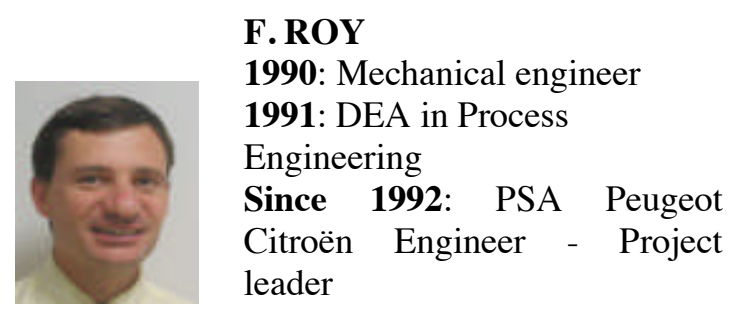

J.-P.POIROT-

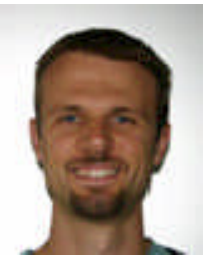

CROUVEZIER

1996: Chemical engineer

2000: $\mathrm{PhD}$ in Process

Engineering

Since 2001: $R \& D$ engineer in fuel cell lab at CEA.

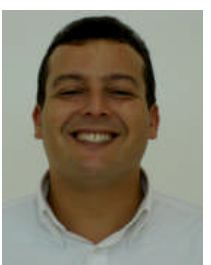

\section{S. GARNIT}

1996: Civil engineer 2002: $\mathrm{PhD}$ in management of complex energy systems Since 2002: PSA Peugeot Citroën engineer - Responsible of FCS conception 